\title{
Corona Virus Pandemic Outbreak and Performance of Selected Nigerian-Based Organizations
}

\author{
GABRIEL, JUSTIN MGBECHI ODINIOHA, PhD \\ Senior Lecturer, Department of Management, Faculty of Management Sciences, Rivers State University, Port \\ Harcourt, Nigeria \\ EKEZIE, CHIBUEZE MACRAE DAVID; YAKIE, EBISIDOR FAVOUR; ELECHI, BOBBY CHIME; \\ OKPOSUOGU, CASCA NNA; LUCKY-KORMENE, CHRISTIANA ONUABUCHI; WORGU, \\ VIVIAN OGECHI; ALABO, ESTHER \\ Doctoral Students in the Department of Management, Faculty of Management Sciences, Rivers State \\ University, Port Harcourt, Rivers State, Nigeria
}

\begin{abstract}
This paper investigated the impact of the COVID 19 pandemic on the performance of Nigerian-based organizations. The methodology for the study was qualitative and its design was phenomenological. Data was generated using the observation and interview tools from 25 referents purposively selected and distributed equally across 25 organizations from 5 industries (manufacturing, banking, oil and gas, hospitality and telecommunication industry). Analysis was thematic and based on a 2-level coding system (open and axial codes). The findings of the study report that the experiences of organizations and the impact of the COVID 19 pandemic on their operations, customer relations and employee relations, differed substantially across their industries. Evidence showed that this difference was also reflected in their choice of response and strategic approaches towards addressing the crisis. It was concluded that organisations must be flexible and at alert in taking the right decisions in the quickest possible times always as they respond to the impact of this pandemic.
\end{abstract}

Keywords: COVID -19 pandemic, business activities, operational performance, customer relations, employee relations

DOI: $10.7176 / \mathrm{EJBM} / 12-23-09$

Publication date:August $31^{\text {st }} 2020$

\section{Introduction}

Organizations are constantly besotted by factors beyond their control, with unpredictable outcomes. One fundamental goal of the organization is survival, and to survive, organizations must be able to advance responsive approaches that help them thrive through tough and challenging periods or times (Bryson, 2018). One of such tough times is the recent corona virus pandemic (termed the COVID 19), which within a short period of time, has swept across continents, ravaging lives, social and economic exchanges and as such negatively impacting on businesses (Brown, 2020). With origins traced to Wuhan, in China, reports show that within a period of approximately seven (December, 2019 - date) months, the COVID 19 virus has spread across almost all countries on the globe with very few without reported cases (NCDC, 2020). Despite efforts tremendous efforts and investments towards curbing the spread, its impact on the citizenry, industries and economy of nations has in most cases been devastating (WHO, 2020).

At the macro level, governments previously enforced strict lockdown protocols which overtime; due to the poor level of adherence expressed by the citizenry and the repercussions of the use of force in most nations (e.g. Nigeria, India, Britain, USA etc.); increasingly lost its efficacy. Recent efforts have focused on the enforcement of social distancing, the use of face masks or shields and the control of movement beyond certain periods of time (e.g. curfew) (Gralinki \& Menachery, 2020). One of the reasons for the ease down of lockdowns on social and economic activities was the impact of such on the businesses and industries - and as such the implications of such on the economic wellbeing of the nation (Brown, 2020). Within periods of high and strict lockdown enforcements, most organizations were forced to sack or relieve most of their staff, close branches and even reduce the emolument for retained staff. This is because most businesses thrive on physical interactions, distribution of tangible products and services through road or air transport, and in other levels of economic exchange on a physical plane or process.

From the foregoing it is apparent that the COVID 19 pandemic has had a macro descending effect from the national, sectorial, industry level to the organizational or meso level, and currently, there is a meso ascending effect from the organization, industry, sectoral level on the economy of the nation - this arguably could be considered as one of the primary reasons for the reconsideration of the public control policies and lockdown relaxation by most countries. It is therefore understandable, that for one to assess and fully grasp the implications of the COVID 19 impact on nations and their economies, one must begin at the meso level - which fundamentally, within the context of this paper, describes social and economic based groups which can be considered as pivots to the wheels of the nation's economy. An understanding of the effect of the COVID 19 pandemic on their economic 
activities as well as their response strategies in dealing and coping with the times is therefore key to understanding the wellbeing and resilience of not only the organizations themselves, but as earlier noted, the resilience of their related industries, sectors and overall national wellbeing.

\section{Purpose and Objectives of the Paper}

The purpose of this paper is therefore to address the implications of the COVID 19 pandemic on Nigerian organizations. This includes an assessment of the impact of the pandemic on businesses and the strategies and actions adopted by organizations in tackling the negative effects of the virus. The objectives of the paper are stated as follows:

i. To ascertain how the COVID 19 pandemic has impacted the operations of organizations in Rivers State

ii. To examine how the COVID 19 pandemic has affected the customer relations of organizations in Rivers State

iii. To examine how the COVID 19 pandemic has influenced the employee relations of organizations in Rivers State

iv. To identify the strategies adopted by organizations in addressing the impact of COVID 19 pandemic in Rivers State

\section{Research Questions}

The following research questions are advanced in view of the objectives and as such serve as guide in the actions and focus of the study:

i. How has the COVID 19 pandemic impacted the operations of organizations in Rivers State? ii. How has the COVID 19 pandemic affected customer relations of organizations in Rivers State?

iii. How has the COVID 19 pandemic influenced the employee relations of organizations in Rivers State? iv. How have organizations responded in addressing the impact of COVID 19 pandemic in Rivers State?

\section{Conceptual Framework}

The conceptual framework for this paper details the conceptualization and relationship between the variables of interest and also demonstrates using the figure 1, assumptions about the relationship between the variables. The conceptualization of the COVID 19 pandemic involves not only the actual effects of the virus on the citizenry (e.g. health complications and death) most of which are workers within some of the organizations of interest; it also involves the fear and sense of insecurity associated with the pandemic (WHO, 2020; NCDC, 2020). The conceptualization for the performance of Nigerian -based organizations is based on the four-point model of the balance score card - detailing the financial, customer/market, employee/process, and the operations/adaptive features and performance points for the organization (Cole, 2002). However, given the emphasis on secondary and historical data for the financial measure and its underlying quantitative features; this paper addressed only the operations, customer relations and employee relations measure of the performance or wellbeing of the organizations. The assumed relationship between these factors are illustrated on figure 1 as follows:

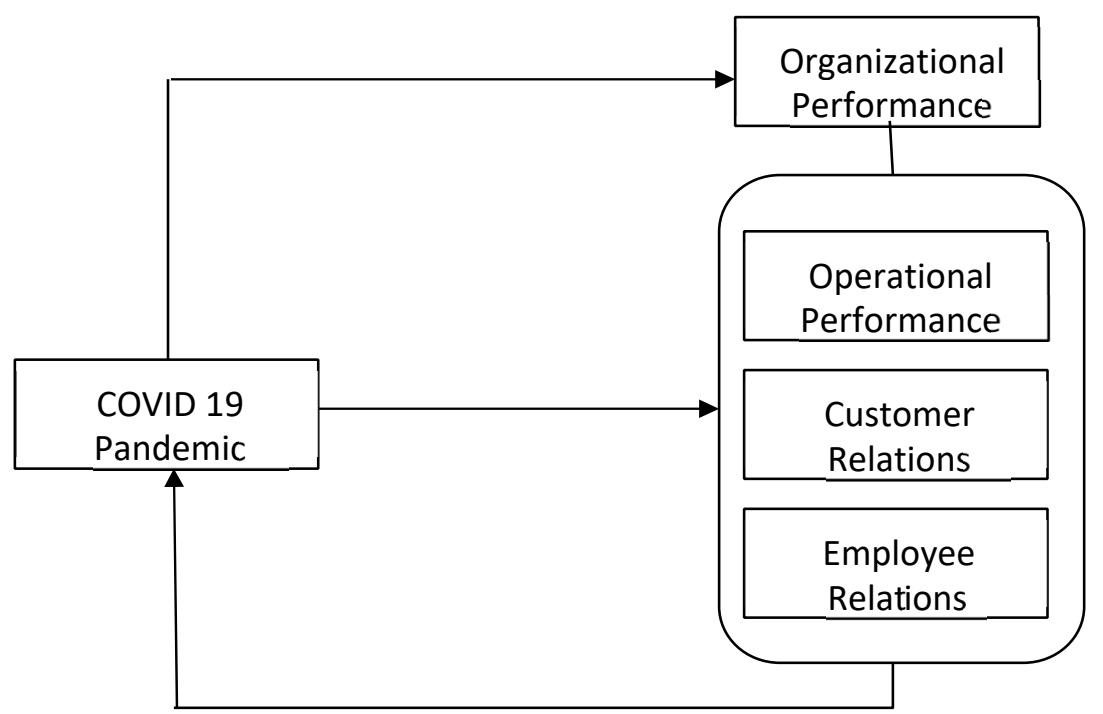

Figure 1: Conceptual framework for COVID 19 pandemic and organizational performance

Source: Researcher's desk (2020) with measures of organizational performance based on the balanced scorecard performance indices (Cole, 2020) 
As illustrated, on figure 1, the relationship between the COVID 19 pandemic and organizational performance as investigated herein is bi-directional. In other words, the interest of this paper lies not only in establishing and ascertaining the impact and outcomes of the effect of the pandemic on specific organizations in Rivers State, the focus also extends towards identifying the actions of these organizations in curbing and addressing the effect of the COVID 19 pandemic on their functions. This two-way relationship is expressed using the arrows which depict impact from factor $\mathrm{x} \rightarrow \mathrm{Y}$ and then feedback from $\mathrm{Y} \rightarrow \mathrm{x}$. Where $\mathrm{x}=\mathrm{COVID} 19$ pandemic and $\mathrm{Y}=$ Organizational performance.

\section{Literature Review}

Theoretical Baseline (Situational Crisis Communication Theory): The baseline theory adopted in addressing the impact of the COVID 19 pandemic on the performance and wellbeing of organizations in this study is the situational crisis communication theory (Coombs, 2014). According to Coombs (2014) a crisis can be based on internal or external events. An internal crisis could stem from fire outbreaks, chemical leakage or other forms of disasters within the organization. Crisis based on external factors comprise events such as earthquakes, street protests, armed robbery and even the spread of highly contagious diseases on a global scale such as that of the COVID 19 pandemic. Both forms of crisis, nonetheless, often have serious implications for the functionality of the organization and in most cases lead to loss of assets, loss of lives, lawsuits against the organization and even a shutdown of operations (Coombs, 2014; Boin, Stern \& Sundelius, 2016).

The survival and sustained performance of the organization is therefore one premised on (a) the severity of the crisis, (b) the organization's understanding of the severity, (c) and the organizations adoption of responses that match the level of severity expressed in the crisis. These three factors define the core argument of the situational crisis communication theory, which according to Coombs (2007) are the basis for the organization's success and survival in times of crisis. The nature and severity of crisis situations, according to Coombs (2007), differs on various planes. A crisis could be disruptive but with low mortality rate such as in non-violent protests, but at the same time, also disruptive, dangerous and with evident casualties such as in violent protests - both protests, but with evident dissimilar features thus requiring different approaches. A good understanding of the severity of the crisis would guide the decision and choice of the manager or leadership of the organization as to what response strategies are best suited for their situation. In his argument, Coombs (2007) noted that the situation of the crisis should determine the response and some approaches could be considered as over-reactions or poor responses towards crisis management.

The situational crisis communication theory advances two main forms of crisis response strategies in addresses both internal and external crisis events - (a) the primary, and (b) the secondary.

Within the primary crisis response approach, the focus is placed on strategies such as being defensive, ignoring or denying responsibility for the crisis, and rebuilding and strengthening relationships through supportive and collaborative actions. The secondary approach deals more with re-emphasizing earlier adopted primary stances or strategies through the evasion of responsibilities, reiteration of the organization as also a victim of the crisis, and the solidification of partnership through compensation, support and the development of platforms for increased interaction and cooperation (Boin et al, 2016). These offer a broad framework useful to this paper in its investigation of the impact of the COVID 19 pandemic on the wellbeing and performance of Nigerian-based organizations as well as their responses or non-response to the crisis. The situational crisis communication theory also guides the thought-process of this study along the lines of understanding the level of responsibility or evasiveness expressed by the leadership of the organizations.

\section{The COVID 19 Pandemic}

The spread of the mutated Corona virus which was first identified in December, 2019 (COVID 19), at the time of this paper, has a global impact rate of over 11 million confirmed cases, and over 500,000 related death cases. The spread of the virus was confirmed a pandemic by the world health organization (WHO) in March, 2020 (WHO, 2020). However, criticism has continued to trail the management and control of the spread of the virus by WHO and government authorities (Brown, 2020). Apart from the observed severity, rapid spread and high mortality of the virus, most governments were either in denial of its impact on their states, or acted nonchalantly with regards interstate and international movement. This poor response is considered as one of the major factors behind the spread of the virus. Another reason has been the politicizing of the spread with some parties exaggerating actual cases for more financial support. Yet still, like a conflagration, the spread of the virus has continued undeterred with notable and prominent personalities falling victim to its gruesomeness (Brown, 2020).

Reports (WHO, 2020; NCDC, 2020) show that while the western and developed parts of the world were the first regions to be hit by the virus, its spread and manifestation within Africa was rather slow at first. Some attributed this to the climate of the country and others, to claims of stronger levels of immunity in the black man. Thus, it was considered initially as a white man's curse and one re-engineered as a bio-weapon against enemy nations. Unfortunately, the increased pace and spread of the virus within African nations today appears to be of a 
major concern to interest groups and organizations. This is because, apart from the poor level of literacy and high poverty riddling the state and living conditions of the citizenry of these nations, there is also a lacking in health infrastructure and equipment required for tackling a pandemic of this magnitude (Brown, 2020). A good example is the failed attempt by most African nations such as Nigeria, to emulate western countries in their adoption of the lockdown as a response strategy in addressing the spread of the various and as such, the use of palliatives in ameliorating the suffering and conditions of their citizens. Apart from the issue of funding in Nigeria, its corruption and poor leadership have been observed to negate such responses and, in that manner, mitigate against its projected outcomes.

One finds a failure of crisis response strategies based on the earlier specified framework of the situational crisis communication theory. This follows the failure of authorities to understand the severity of the pandemic as well as their adoption of responses that are mis-matched (particularly with regards to their own features and capabilities). Current redress of the situation suggests a position and response more likened to that of evasiveness of responsibility such as reflected in the Nigerian approach with governments intended reopening of schools but their position that "if parents still fear for the safety of their children then they should not send them to school" (TrackNews, 2020). Not only does action, much like other recent actions, shift responsibility from the government to its citizens, it also smacks of the government indecision and helplessness in addressing and handling the situation. At this level, the concerns are those of a macro nature, yet as earlier observed, the meso level (comprising group and organizational actions) is a rather critical aspect of the situation given the noted implications of the COVID 19 pandemic on organizations and the resulting impact of such on the economy of nations. This is as organizations are considered the key players in the COVID 19 crisis situation as their functions and market interactions one fundamental in shaping social activities despite the COVID 19 pandemic.

\section{The performance of selected Nigerian-based Organizations}

Performance is a reflection of how well an organization is functioning. A performing organization, according to Cole (2020) is that which is not only able to meet its financial expectations, but that which also has a healthy and functional operational process, as well as good working relationship with its employees and customers. This is because a performing organization satisfies its customers and through its achievements and actions, demonstrates competence and as such reassures its employees of their security and futuristic placement (Olawale, 2014). Literature is condensed with a focus of organizational performance which detail only the financial and market aspects of its health in the areas of return on investment, market share, return on assets etc., however, Madu (2013) argued that the financial goals of the organization should be the least of its worries as such outcomes are inherently tied and flow directly from its relationship with its customers, employees and how well its operational actions can be considered as efficient and effective. A performing organization is therefore that which not only has the capacity for producing and servicing its market through quality products at the required quantity and time, but that which is also able to maintain trusting and healthy relationships with its employees and operate optimally within its context.

The foregoing definition and conceptualization of performance is essential, especially in its application to the activities and functions of most organizations in Nigeria. This is as Jibai (2018) observed that while most organizations in Nigeria, especially key service providers, which are noted for sustained functions and high revenues; their poor relationship with customers and employees disqualifies them as performing organizations. A good example is the Power holding company of Nigeria, which despite their increasing conflict with customers due to poor and erratic power supply, yet generate substantial revenue on a daily basis. Their performance as such is hinged on only the financial index of the balanced scorecard as other indices such as employee and customer relationships are noted to be very poor. Their poor service quality is also traceable to their weak operational performance. Another example of misguided performance conceptualization is that attributed to the banking sector. This is as Okpu and Jaja (2014) identified the Nigerian banking industry as one marked by poor employee relations and exploitative contracts. Despite reported annual revenues and increasing customer satisfaction, most banks in Nigeria are noted for their high dependence on contractual or non-permanent staff, thus engaging in highly exploitative actions and policies. It is as Okpu and Jaja (2014) pointed out, that most workers opt only for banking jobs out of desperation and the lack of better alternatives.

\section{COVID 19 Pandemic and the performance of selected Nigerianbased Organizations}

The impact of the COVID 19 pandemic on the business and economic activities of organizations is such that has not only crippled the economy in most nations but has further amplified crime levels and frustration due to closed businesses and loss of jobs. Apart from the associated fear of infection and death, most workers are further subjected to increased levels of poverty and vulnerability (Africanews, 2020). This is because, reports have indicated a spike in job loss over the last 3 months (April - date) in Nigeria, with most organizations downsizing to only key staff. While this experience isn't reported to be as evident in the public sector, there has nonetheless been a widespread position on controlled movement and gatherings, leading to a closure of schools, churches and 
other institutions within the country (Africanews, 2020; TheAfricacareport, 2020). This is as studies point to a growing decline in two main sectors of the economy - the primary (agriculture, mining etc), the secondary (manufacturing, construction etc), and the tertiary (banking, hospitality, education, research etc). On the other hand, the quaternary (telecommunication, etc.) is reported to have increased substantially. This could be due to nature of its functionality and focus on virtual services and information management - a good indication for the direction of an effective response.

Recent trends within the entertainment industry shows most movies have postponed their release dates due to the restrictions on group gatherings and most cinema and drama theatres have been shut down (Africanews, 2020). Manufacturing organizations, fast-food restaurants, and tertiary institutions are some of the organizations with the worst impact. One could trace this outcome to their noted use of groups or gatherings, as well as their reliance on the transportation and distribution of materials, and products across states and a wide spread of geographically dispersed locations. The pandemic as such, has impacted and prevailed over their operations. The impact has also affected the nature of their services and product offerings to their customers as most products or services are currently inaccessible to their market (Africanews, 2020). This has impacted on their profitability and revenue generation, making it difficult to compensate their workers - creating growing rifts between management and their staff in several organizations, with most organizations either closing or suspending branch activities. The pandemic has as also impacted negatively on the performance of most Nigerian organizations, with only very few, appearing to be advantaged given their informationdriven features (TheAfricacareport, 2020; NewsUN, 2020).

\section{Methodology}

This paper adopts a phenomenological design in its investigation of the phenomena of interest (Holliday, 2007). This is as its approach is based on a qualitative methodology as reflected in an interpretivist underlying philosophy (Hakim, 2000; Holliday, 2007). Participants for the study are purposively selected from 25 organizations, distributed equally (5 each) across five (5) key industries and also across the five selected sectors of the economy. The distribution and categorization of the organizations and their related industries and sectors are presented as follows in table 1 as follows:

Table 1 Distribution for study units

\begin{tabular}{|c|c|c|}
\hline Sectors & Industries & Organizations gas Belema oil \\
\hline Primary & Oil and & Seplat \\
\hline \multirow[t]{3}{*}{ Sector } & industry & Atlas \\
\hline & & Excel \\
\hline & & Pan Ocean \\
\hline
\end{tabular}

\begin{tabular}{lc}
\hline Secondary & Manufacturing \\
Sector & industry
\end{tabular}

\section{Dufil Ltd}

Nigerian Breweries

Nigerian bottling company

BUA Nigeria Ltd

First Aluminium

\begin{tabular}{lc}
\hline Tertiary & Banking industry \\
Sector & \\
& Union Bank \\
Access Bank \\
Zenith Bank
\end{tabular}

First Bank Nigeria

Guarantee

Bank of Nigeria

Trust

Hospitality Novotel Hotel industry Juanita Hotel

Golden Tulip Hotel

Landmark Hotel

Ogeyi's Place

\begin{tabular}{lll}
\hline Quaternary Sector & $\begin{array}{l}\text { Telecommunication MTN Nigeria } \\
\text { industry } \\
\text { Smile Network }\end{array}$ & Globacom Nigeria \\
& 9 Mobile Nigeria & Airtel Nigeria
\end{tabular}

One (1) participant are purposively selected from these identified organizations as referents in the study, - 
giving a total of 25 participants from 25 organizations within 5 industries. Participants were selected on the basis of their availability and referent positions within their respective organizations. Two instruments were used in data collection, (a) observation and (b) interviews. For observation, personal visits were paid to the target organizations in view of assessing their identifiable response features, and while in the process, detailed actions were noted and recorded. For the interviews, open-ended questions were designed using clear and brief questions that asked direct questions relating to the issues of interest. Selected participants were as such engaged in a $10-20$-minute interview session focusing on their experiences, observations and interpretations of the COVID 19 pandemic impact on their organizations. Data analysis was thematic with a two-level coding format - (a) open codes: for assessing the initial responses and experiences of the referents with regards to the issues of interest, and (B) axial codes: for linking such experiences, and advancing meaning in a way that identifies a position and justifies an outcome. The QSR Nvivo software was utilized in the arrangement and management of the qualitative data.

\section{Data Report}

Data reporting adopts a traditional report format. Reporting also adopts a structure aligned with directly addressing the research questions and theme of the study. A total of four questions were asked; hence, the report is based on four sub-sections - each focused on a priori themes and concerns of the study. Report also allows for a breakdown in line with the unique attributes of the industries as the goal is to also identify the unique experiences and counter measures of these industries. Table 2 below demonstrates the coding system, number of codes and the related themes and sub-sections reported in the study. Table 2: Coding system and report

\begin{tabular}{|c|c|c|c|c|}
\hline Themes & Axial codes & Open codes & Sources & Refs \\
\hline \multirow{4}{*}{$\begin{array}{l}\text { COVID } 19 \text { pandemic and } \\
\text { operations }\end{array}$} & \multirow{3}{*}{$\begin{array}{l}\text { Negative impact on } \\
\text { Operations }\end{array}$} & Suspension of contract services & 7 & 12 \\
\hline & & Suspension of Operations & 22 & 41 \\
\hline & & Disruption of Services & 8 & 15 \\
\hline & $\begin{array}{l}\begin{array}{l}\text { Increased control of } \\
\text { operations }\end{array} \\
\end{array}$ & $\begin{array}{l}\text { Additional control measures in } \\
\text { Operations }\end{array}$ & 9 & 23 \\
\hline \multirow{5}{*}{$\begin{array}{l}\text { COVID } 19 \text { pandemic and } \\
\text { customer relations }\end{array}$} & \multirow{2}{*}{$\begin{array}{l}\text { Negative impact on } \\
\text { customer relations }\end{array}$} & Impatience over control measures & 34 & 41 \\
\hline & & Frustration of reduced services & 21 & 27 \\
\hline & \multirow{3}{*}{$\begin{array}{l}\text { Increased pressure for } \\
\text { online service }\end{array}$} & Customer complaints & 18 & 19 \\
\hline & & Network challenges & 29 & 36 \\
\hline & & Network migration and porting & 4 & 13 \\
\hline \multirow{4}{*}{$\begin{array}{l}\text { COVID } 19 \text { pandemic and } \\
\text { employee relations }\end{array}$} & \multirow{3}{*}{$\begin{array}{l}\text { Negative impact on } \\
\text { employee relations }\end{array}$} & Staff reduction & 19 & 22 \\
\hline & & Salary cuts & 32 & 39 \\
\hline & & Distrust of Management & 13 & 21 \\
\hline & $\begin{array}{l}\text { Employee feeling of } \\
\text { relevance }\end{array}$ & Perceived job Security & 21 & 38 \\
\hline \multirow[t]{4}{*}{$\begin{array}{l}\text { COVID } 19 \text { pandemic and } \\
\text { Organizational response }\end{array}$} & health-based & Increased health protocols & 29 & 30 \\
\hline & \multirow{2}{*}{$\begin{array}{l}\text { Staff and customer } \\
\text { support and reassurance }\end{array}$} & Staff briefings and reassurance & 11 & 16 \\
\hline & & $\begin{array}{l}\text { Increased online support systems } \\
\text { and learning Platforms }\end{array}$ & 19 & 21 \\
\hline & Security support & $\begin{array}{l}\text { Increased of use of security } \\
\text { personnel }\end{array}$ & 9 & 14 \\
\hline
\end{tabular}

Below demonstrates the coding system, number of codes and the related themes and sub-sections reported in the study. Table 2: Coding system and report

\section{Coding}

Coding is used for categorization of data i.e the response gotten from the field work; this data was arranged into groups.

There are two types of coding used

1. Open coding

2. Axial coding

\section{Open Coding}

Open coding: Basically, you read through your data several times and then start to create tentative labels for 
chunks of data that summarize what you see happening (not based on existing theory - just based on the meaning that emerges from the data). Record examples of participants' words and establish properties of each code. It is actually used for the categorization or arrangement of data gotten from the field response.

\section{Axial Coding}

Axial coding consists of identifying relationships among the open codes. What are the connections among the codes?

Also, where connections between the open codes are examined, and used to create larger codes or eventually themes (in the selective coding step).

More so, it is used for the categorization of data related to the research questions.

\section{Sources}

The number of persons that responded during the interview

\section{References}

The number of times the respondents responded in a particular way saying the same thing.

e.g

\section{i. How has the COVID 19 pandemic impacted the operations of selected industries in Rivers State?}

This question addressed the impact on the operational activities and functions of the organization. Its focus is on ascertaining how much and in what ways the COVID 19 has affected the organizations functionality and operations within its context.

(a) Oil and gas industry: Within the oil and gas industry, referents observed that there was a high level of uncertainty as regards when to act and when not to. Although, their operations were considered as essential and as such operations continued, referents noted that actions were highly controlled and protocols increased. Furthermore, there was an increased level of checks and health assessments on personnel, especially during conveyance or movements to rigs or sites. Nonetheless, operations continued as before with interstate movement passes granted even during the interstate travel bans. One referent noted that there was an increased level of escorts and military personnel in their activities as well.

(b) Manufacturing industry: In the manufacturing organizations examined, referents identified operations as being substantially deterred by the COVID 19 pandemic. This is as referents observed that their organizations relied heavily on supplies which sometimes were sourced from outside the State and also had markets outside the State - hence the lockdowns, and interstate travel bans had a major negative impact on their operations. One referent also observed that given the government actions on movement, most manufacturing firms also had to suspend their activities and staff were sent back to await improvements to their conditions. Operations for manufacturing firms were as such mitigated by the COVID 19 pandemic.

(c) Banking industry: With regards to the banking industry, referents admitted to a slowdown of operations and activities. Although, considered an essential service, one referent noted that what's the bank without its customers? Another referent noted that there was a significant drop in transactions as most people are not too comfortable with the mobile apps and internet banking and as such had to wait till the lockdown was eased to visit their banks for activities. Most staff contract staffs and services were suspended as the banks at this period were noted to work mostly with their key or permanent staff.

(d) Hospitality industry: The hospitality industry is considered as one of the most affected by the COVID 19 pandemic. Referents admit to having their services suspended during the high-point of actions geared towards the control of the pandemic. The government actions were very decisive on hotels as referents pointed to the demolishing of hotels as a serious action taken by the government on hotels for flouting orders, some staff were also laid off and only key maintenance services were carried out such as the cleaning and servicing of equipment by resident staff, and other minor services to existing occupants. All major operations were as such placed on hold.

(e) Telecommunication industry: The telecommunication industry is as stated by referents to have experienced a demand spike. Although referents disagreed over staff attendance and presence at regional offices, with some stating a reduced number of staff and others stating all staff were expected to be present - all referents agree to the increased level of demand for services ranging from data subscriptions to call credit subscriptions. Referents observe that this was most evident during the lockdown as subscribers appeared to opt for higher data amounts and made more calls during the period. Although this impacted on their capacities as they were forced to address issues of poor network traffic through 
system upgrades and client migrations. However, there was also a high level of network porting and a drop in new sim registrations.

ii. How has the COVID 19 pandemic affected customer relations of selected industries in Rivers State?

In this section, questions are aimed at assessing the impact of the COVID 19 pandemic on the relationship between the organization and its customers, especially in line with market changes, demands and service quality.

(a) Oil and gas industry: Referents within the oil and gas industry admit to a high drop and loss of revenue due to their loss of customers and clients during the COVID 19 pandemic. This is because most businesses, institutions and industries function using their products - thus, with a closure and shut down of these businesses, there was a significant drop not only in the usage or utility of the product but also in its price. As such, one could say the pandemic has resulted in a strained relationship between oil and gas organizations and their customers.

(b) Manufacturing industry: Referents in manufacturing organizations also share in the experience of the oil and gas industry. This is because the pandemic, and the resulting shut down has impacted on their production and supply levels and despite the noted panic buying prior to the shutdown, profitability has not been as substantial as before. Unfortunately, most firms in a bid to compensate for their loss of capital during the period, took advantage of the panic period and increased prices, further causing a rift between customers and the firms. This is as supplies such as bread, indomie, beverages and drinks were sold out during the periods with no restock at warehouses due to the closed borders and lack of access to supply locations

(c) Banking industry: Within the banking industry, referents noted that there was an increased strain on the relationship between staff and the customers of the bank. Apart from increased complaints over poor services, slow networks and error issues over online platforms - given the fact that most individuals were forced to learn and use online platforms as a result of the pandemic, other issues stemmed from that of crowd control and coordination at the bank premises during lockdown relax periods. As such, there were instances of customers requesting for their accounts to be closed or all their money transferred to other banks. While some referents however admitted to some level of bearing and understanding on the part of the customers, there was nonetheless an all-round level of grievance and customer dissatisfaction with most banks.

(d) Hospitality industry: Referents within the hotel industry noted that while initially, protocols were installed to check guests and clients checking into or visiting the hotel, prior to the suspension of their services; customers grew uncomfortable and tired of the process - resulting in confrontations with staff over the use and need for such protocols. Upon the order for suspension of services, this rift increased as occupying guests were forced to cope with a reduction of services and in some cases amenities such as power. While no new guests were admitted and some staff services suspended, customers yet expected their services to be optimal, which according to referents was not possible. This led to a highly discomforting relationship between staff and hotel guests and most guests left immediately other alternatives and options were made available.

(e) Telecommunication industry: Referents opinion and position on the nature of their relationship with their customers within the telecommunication industry was mixed. Some referents noted that one defining factor was the customers experience of service which either led to their porting to other networks, or their increased expenditure on data services, and the trial of other services. Nonetheless, most of the firms admitted to a sustained level of interaction and relationship with their customers during the period.

iii. How has the COVID 19 pandemic influenced the employee relations of selected industries in Rivers State?

The related question addressed issues related to the relationship between management and its employees as a result of the impact of the COVID 19 pandemic on the functionality and wellbeing of the organization

(a) Oil and gas industry: Referents within the oil and gas sector noted there were a lot of concerns raised as regards job security and the sustainability of existing operations given the poor demand and drop in the price of oil. While substantial reductions were made in staff use and compensation reduced, most organizations did their best to maintain staff levels. Nonetheless, observed reductions in staff use and compensation during the pandemic affected staff perceptions and raised fear and distrust within the organization. As a result of this, management and staff relationships were strained.

(b) Manufacturing industry: Manufacturing firms witnessed high evidence of conflict between staff and 
management, primarily due to salary cuts and the reduction in staff size. One referent noted that the situation gave rise to a staff versus management condition as workers felt they could no longer trust their leaders. Incidences also gave rise to litigations with regards to non-payment of salaries over a long period of time and then the use of the pandemic period as an excuse to lay off staff. The evidence within the manufacturing industry therefore reflects that of poor relations between staff and management.

(c) Banking industry: Within the banking industry, referents affirmed that although there were incidences of salary cuts and layoffs, the categories of staff affected were the casual workers or temporary staff of the banks. According to referents, only few banks suspended branch offices but however reassured their permanent staff of call-backs once the branches were re-opened. Yet still, there were occasions of disagreement within some branches over shared roles and responsibilities given the layoff of contract staff as more responsibilities were heaped on permanent staff without any substantial increment in their emolument. This also caused a rift between management and employees.

(d) Hospitality industry: Employee relations within the hospitality sector, especially as expressed within hotels is noted in some cases to be frictional and in other cases as being understanding and trust-based. According to one referent: it is primarily a function of how you handle and address the situation. Referents affirm to some cases of controversy over those who were retained for core services during the lockdown and those who were asked to wait for call-ups after the lockdown. While in most cases, workers expressed discomfort and fear over their jobs, there was a substantial level of cooperation based on shared understanding of the situation.

(e) Telecommunication industry: Employee relations within the telecommunication industry has be sustained without much conflict or fears. Referents stated that while the COVID 19 pandemic has raised concerns within other industries with regards to employee use and functions, the responsibilities of the telecommunication industry have on the other hand increased and as such offered reassurance of its viability and as such the security of jobs. This has enhanced the employee - management relationship. This is as the mounting pressure to the increased demands has also enhanced workers sense of duty and justified their relevance to their respective organizations.

iv. How have organizations responded in addressing the impact of COVID 19 pandemic industries in Rivers State?

The related question addressed in this section relates to examining the responses and strategic decisions adopted by organizations in dealing with the challenges and evidence of the COVID 19 pandemic

(a) Oil and gas industry: Referents noted that one of the key response strategies adopted by their organization in addressing the COVID 19 pandemic has been their increased involvement of health personnel in consistently testing and assessing the health of the workers. Also, their firms have relied heavily on both military and police for their continued assess to work stations and sites as a way of avoiding harassment from other government authorities and agencies. Options were also made available for staff who were not comfortable with existing work demands during to COVID 19 pandemic to resign or opt for other work units without direct field activities as policies within most of these organizations were redesigned to allow for suitable transfers and re-assignments.

(b) Manufacturing industry: Within the manufacturing industry, key actions, according to referents adopted by management comprised of the use of defensive statements presenting the outcome of organizational decisions as based on their lack of control of the situation. However, key staff were maintained to continue with availing product demands and supplies - especially those within the state. Staff were offered apologies for the situation with reassurances of their call-up once the organizations were more stable and able to function accordingly. Some roles were reduced to control for loss and inefficiency and some products with low demands were offered at giveaway prices to avoid waste in the warehouses.

(c) Banking industry: The banking industry primarily focused on the adoption of social distancing control at their offices and improved online customer care, given the noted shift and increased demands on internet platforms. A number of refunds and corrective measures were advanced to satiate customers with transfer issues and application interfaces were upgraded to offer stage by stage learning and app utility for users online. Staff were also briefed on the situation and the continued effort of management to ensure their safety and security within the premises of the bank. Attention was also drawn to the increased activities of fraudsters during the COVID 19 period and effort was also channelled towards informing and creating awareness about such activities through text messages, and online reminders by the banks. Health protocols were also increased and the use of face mask enforced and made compulsory just as hand sanitizers were installed at the banks. 
(d) Hospitality industry: For hotels, one of their key response strategies was their briefing of staff and customers of the situation and their online reassurance of services and improved standards after the lockdown episodes. In some cases, new and existing guests were treated to special meals and drinks in recognition and appreciation of their continued patronage despite the noted service disruptions during lockdown periods. Additionally, health protocols were increased as most hotels install sanitizers at entrances and halls to facilitate constant use. Staff training was also carried out in some hotels on how to relate and interact with customers especially during the trying period.

(e) Telecommunication industry: The telecommunication industry, as stated by referents acted in the direction of increased demands by increasing their online support systems, and also competitively advancing their data subscription packages up to about $100 \%$ data additions at the same price. Additionally, effort was made to ensure customers were constantly informed on changes in data charges and possible promos available during the period.

\section{Discussion of the Findings}

The findings of this paper serve to not only identify the impact of the COVID 19 pandemic on the activities of organizations within 5 different industries in Rivers State, but also to specify the actions and responses of these organizations in addressing their crisis situations. The results demonstrate that most of the organizations particularly those within the manufacturing, and hospitality have had their operations and services suspended. This is as other industries have experienced modifications to their functions and structures so as to be able to function and address the crisis. Notable amongst this impact is the severity of the pandemic on the market of all these industries with the telecommunication industry appearing to have an opposite outcome. The study identifies these as resulting in profit drops for most organizations such as banks, oil and gas firms and hotels, nonetheless, an increased demand and profit rise for telecommunication firms.

At the same time, these outcomes have impact on customer and employee relations for the organizations with organizations within the manufacturing and hospitality appearing to be the most affected given their service suspensions and shutdown of operations. One finds that within such crisis, the response strategies play a great deal in sustaining trust and ensuring that patronage is not lost after the COVID 19 pandemic. The findings as such reiterate the assumptions of the situational crisis communication theory (Coombs, 2014; Olawale, 2014), affirming that contexts differ and so should the approach towards quelling crisis situations within industries and sectors that differ substantial. The findings in this vein demonstrate the unique experiences and encounters of these industries and their distinct interpretations and approaches in addressing the crisis and challenges spurred on by the COVID 19 pandemic (Brown, 2020).

\section{Conclusion}

It is a noted outcome that the experiences of organizations differ in terms of the COVID 19 pandemic and with regards to their related industries. These differences are anchored on their forms of operations, the nature of their services and their role or essentiality within the period of the pandemic. In this light, it is the position of this paper that crisis event such as the COVID 19 offers several implications for organizations based on their distinctiveness, which in turn defines their relative functionality and relevance. Hence, one of the ways a government can effectively coordinate and develop policies for managing such outbreaks is to be cognizant and considerate of the variety of implications their decisions and policies hold for various organizations. Effective controls and strategic responses at the macro and meso level would therefore be most compatible and suitable where decision frameworks are accommodating of the differences in the industries and their interpretations or experiences of a crisis situation.

\section{Recommendations}

We recommend the following from this study:

1) That Manufacturing industry should go for local products as a substitute for their imported raw materials. This way they will contribute to the development of local content in the country as well as conserve foreign exchange.

2) The Hospitality Industry should adopt 'room-service only' and serve with disposable plates and cutleries to ensure contactless operations and maintain adequate social distancing. Again they should install automatic doors especially at their receptions to ensure automatic opening and closing of doors for the guests.

3) Banking industry should reinforce the use of apps by their customers and equally ensure that the apps are fraud-proof.

This study found that practices, reactions and strategies evolved to adapt to the impact of the novel coronavirus pandemic were industry-specific just as similarity was found among the organisations in various industries. 


\section{Suggestion for further Studies}

Going by the methodology of qualitative data used in this study which was necessitated by the restrictions of human activities during the period of the study, we suggest a quantitative study be carried out in the same organistions.

\section{References}

Jibai A. (2018). Crisis management: A prudent leader for long-term corporate sustainability in the context of insurance companies, Adnan Kassar School of Business. Adnan Kassar School of Business.

Boin, A., Stern, E. \& Sundelius, B., (2016). The politics of crisis management: Public leadership under pressure. Cambridge University Press

Brown J (2020) The Coronavirus Is No 1918 Pandemic; The differences between the global response to the Great Flu Pandemic and today's COVID-19 outbreak could not be more striking. The Atlantic, (3),3.

Bryson, J.M., (2018). Strategic planning for public and nonprofit organizations: A guide to strengthening and sustaining organizational achievement. John Wiley \& Sons

Cole, G.H (2002): Management: Theory and practices (5th Ed.) London, Continuum.

Coombs, W.T. (2014). Ongoing crisis communication: Planning, managing, and responding. Sage Publications.

Gralinski L, Menachery VD (2020) Return of the Coronavirus: 2019- $n$ CoV. Viruses 12, 135.

Hakim, C. (2000). Research design: Successful designs in social and economic research. Abingdon: Routledge.

Holliday, A. (2007). Doing and writing qualitative research. London: Sage Publications Ltd.

https://news.un.org/en/story/2020/06/1065952 https:/www.africanews.com/2020/06/01/nigeria-coronavirushubupdates-covid-19/

https://www.theafricareport.com/28694/coronavirus-effects-ofcovid-19-on-nigerias-informal-economy/

https://www.tracknews.ng/2020/07/dont-send-your-childrento-school-if-youre-not-sure-of-their-safety-fgtellsparents.html

Madu, B.C. (2013). Vision: The relationship between a firm's strategy and business model. Journal of Behavioral Studies in Business, 6, 1.

NCDC (2020) National Interim Guidelines for Clinical Management of COVID-19

Okpu, T. \& Jaja, S.A. (2014). Joint consultation and workers commitment in Nigerian Banking Industry, International Journal of Business and Management, 9(3),53-63.

Olawale, S. R. (2014). Crisis management strategy and its effects on organizational performance of multinational corporations in Nigeria: Empirical evidence from Promassidor Ltd ', European Journal of Business and Management, 6(23), 2222- 2839.

World Health Organization (2020) First data on stability and resistance of SARS coronavirus compiled by members of WHO laboratory network.

\section{Interview Questions}

i. What is your perception of the COVID 19 pandemic?

ii. What effect has it had on your responsibility and role in your organization?

iii. In what ways has the pandemic affected the operational performance of your organization?

iv. What is your view of the government imposed directives on businesses?

v. How have these affected your organization's relationship with your customers? vi. Which areas do you have the highest complaints from customers?

vii. What are your fears and expectations as an employee in this

COVID 19 pandemic period?

viii. How well are staff and management getting along in this COVID 19 pandemic era?

ix. What strategies have been enacted to tackle the challenges posed by the COVID 19 pandemic

$\mathrm{x}$. How effective have these strategies been?

GROUP PHOTOGRAPH TAKEN 10 ${ }^{\mathrm{TH}}$ JULY, 2020 


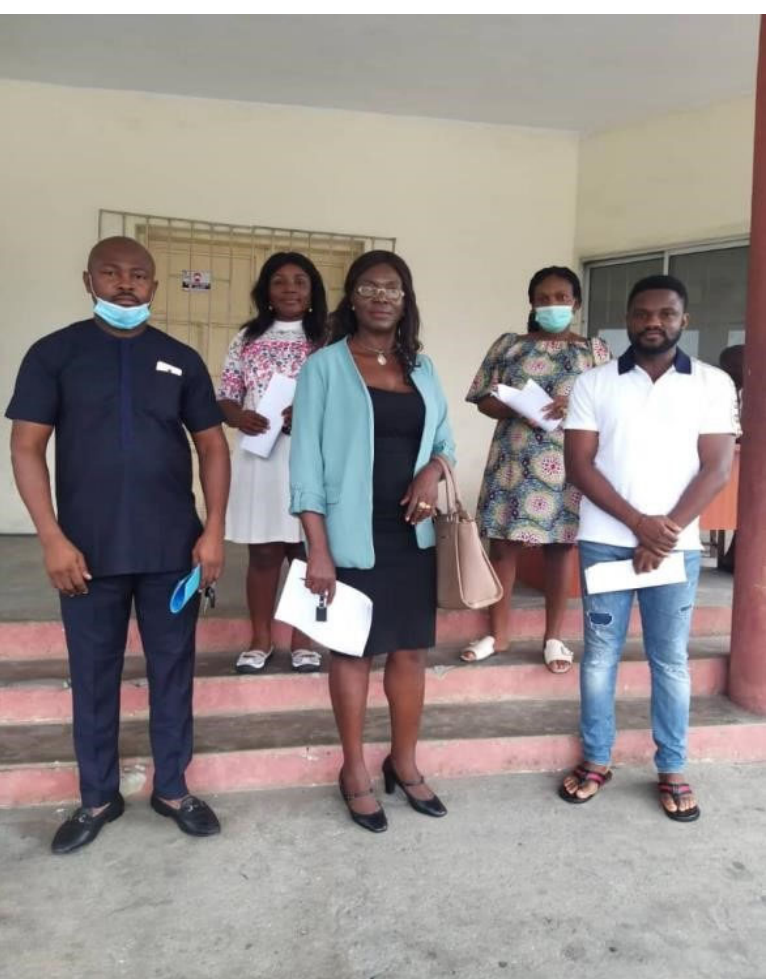

